\title{
Induction of ovulation with hormoral treatment and egg quality in Japanese yellowtail (Seriola quinqueradiata)
}

\begin{abstract}
HISASH CHUDA, ${ }^{1 *}$ TAKAHIRO NAKAO,${ }^{2}$ TOSHIIISA ARAKAWA ${ }^{3}$ AND MICHIYA MATSUYAMA ${ }^{2}$ ${ }^{1}$ Nagasaki Prefectural Institute of Fisheries, Nagasaki 851-2213, Japan (chuda@marinelabo.nagasaki.nagasalkijp), ${ }^{2}$ Faculty of Bioresource and Bioeminonmental Sciences, Kyushu University, Fukuoka 812-8581, Japan, and ${ }^{3}$ Nagasaki Prefectural Government, Nagasaki 850-8570, Japan
\end{abstract}

\section{KEYWORDS: yellowtail, hormoral treatment, artificial insemination, egg quality}

\section{INTRODUCTION}

The total production of yellowtail, Seriola quinqueractiata, has contributed a top share of the marine finfish production in Japanese aquaculture. Despite the great importance of the fish, all juveniles needed have been caught from the wild stock due to difficulties in obtaining fertilized eggs under the captive conditions. However, the catch of wild juvenile (mojako) is urreliable and umpredictable, in fact, for several years culture practices have been seriously affected due to a decrease in catch of wild seedstock. Therefore, a stable supply of Japanese yellowtail juveniles has been highly desirable. Recently, we have developed the techniques for inducing maturation and ovulation and obtaining large quantity of good quality fertilized eggs in cultured yellowtail. The present study describes them briefly.

\section{MATERIALS AND METHODS}

\section{Effects of Water Temperature and Extended Daylength on the Oocyte Grouth}

The fish group A and B were transferred to the experimental indoor tanks (100 or $150 \mathrm{kl})$ in November 13. During the period from mid December to early February, the water temperature of the tanks was kept at $19^{\circ} \mathrm{C}$ (group A) and $16^{\circ} \mathrm{C}$ (group $\mathrm{B}$ ) and the daylength of both groups was set to 16 hours (16L8D). The fish of non-controlled group $(C)$ were kept in the outdoor sea pen $(125 \mathrm{kl})$.

Effects of Different Hormonal Treatment on Quantiny and Quality of Eggs Obtained

Hormonal treatments were applied to induce maturation and ovulation in four-year-old cultured female fish in three different ways: single injection of HCG (500 IU/kg) (Exp. 1), priming injection of HCG (100 or $50 \mathrm{IU} / \mathrm{kg})+$ one day after HCG injection (500 IU/kg) (Exp. II), and single implantation of LHRHa (LHRHa 200 or $400 \mu \mathrm{g} / \mathrm{kg}$ ) cholesterol pellet (Exp. III).
Effects of Initial Oocyte Diameter on Quantity and Quality of Eggs

After confirming the yolk accumulation by monitoring cocyte diameter through ovarian biopsy, all fish in the three experimental groups were injected with HCG $(500 \mathrm{IU} / \mathrm{kg})$. The oocyte diameters of fish in the three experimental groups were 750-794 $\mu \mathrm{m}, 700-746 \mu \mathrm{m}$, and 655-696 $\mu$ $\mathrm{m}$

Relationship between Post-ovulation Time and Fertilization Rate of Eggs in Artificial Insemination

The experimental fish (F-1 to 11) were injected with HCG (500 IU/kg). After confirming the ovulation by gentle abdominal massage, a small volume of ovulated eggs was collected and artificial insemination was performed at 6 hours intervals during 60 hours after ovulation. Then, the relationship between post-ovulation time and fertilization rate was examined.

\section{RESULTS}

Effects of Water Temperature and Extended Daylength on the Oacyte Growth

At the start of the experiment in November, initial oocyte diameter of all the fish in three groups ( $A, B$ and $C$ ) ranged from 100 to $140 \mu \mathrm{m}$. In the fish of group $\mathrm{A}$, the mean egg diameter (MED) reached $712 \mu \mathrm{m}$ on January 31 . In contrast, the MED of fish in the group B showed $696 \mu \mathrm{m}$ on February 20, while the MED in the group C was $717 \mu$ $\mathrm{m}$ on April 21. Thus, gonadal growth was enhanced earlier by maintaining the higher water temperature $\left(19^{\circ} \mathrm{C}\right)$ and long photoperiod (16L8D) during the month of December to February.

Effects of Different Hormonal Treatment on Quantity and Quality of Eggs Obtained

Results of artificial insemination of the eggs from yellowtail 
with different hormonal treatment are shown in Table 1. Egg quality, represented by the fertilization rate and hatching rate, in Exp. I (single injection of HCG (500 IU/kg)) showed the highest values among the three different experimental groups. In Exp. II (priming injection of HCG $(100$ or $50 \mathrm{IU} / \mathrm{kg})+$ one day after HCG injection $(500$ IU/kg)), the largest quantity of ovulated eggs per fish was obtained, however, the egg quality showed the lowest values among the three groups. Quality of the eggs from the fish in Exp. III (single implantation of LHRHa (LHRHa 200 or $400 \mu \mathrm{g} / \mathrm{kg}$ ) cholesterol pellet) was relatively high, but egg number per fish showed the lowest level. Therefore, it is concluded that a single injection of HCG is the most simple and efficient method to induce cocyte maturation and ovulation for obtaining a large quantity of good quality fertilized eggs in yellowtail.

Table 1. Result of artificial insemination of the ego from yellowtail with defferent harmonal treatment in 1998 and 1999

\begin{tabular}{|c|c|c|c|c|c|}
\hline \multirow[b]{2}{*}{ Year } & \multirow[b]{2}{*}{ Experimental group } & \multicolumn{2}{|c|}{ Number of egss per fish $\left(\times 10^{3}\right)$} & \multicolumn{2}{|c|}{ Fertilization Hatching } \\
\hline & & $\begin{array}{l}\text { Total egos } \\
\text { collected }\end{array}$ & $\begin{array}{c}\text { Floating } \\
\text { egos }\end{array}$ & $\begin{array}{l}\text { rate } \\
\% \\
\end{array}$ & $\begin{array}{l}\text { rate } \\
\% \\
\end{array}$ \\
\hline 1998 & HOG injection & $357 \pm 228^{*}$ & $274 \pm 151$ & 80.2 & 58.3 \\
\hline & HOG priming & $463 \pm 136$ & $376 \pm 143$ & 69.7 & 40.6 \\
\hline & LHRHa implantation & $159 \pm 78$ & $141 \pm 74$ & 76.4 & 51.1 \\
\hline 1999 & HOG injection & $528 \pm 330$ & $522+329$ & 95.7 & 57.0 \\
\hline & HOG priming & $576 \pm 256$ & $517 \pm 240$ & 84.3 & 41.4 \\
\hline & LHRHA implantation & $354 \pm 284$ & $347 \pm 287$ & 94.9 & 54.0 \\
\hline
\end{tabular}

$\mathrm{Mean} \pm \mathrm{SD}$

\section{Effects of Initial Oacyte Diameter on Quantity and Quality of Eggs}

Quantity and quality of eggs collected from yellowtail with HCG injection at different oocyte diameters are shown in Fig. 1. A single injection of $\mathrm{HCG}(500 \mathrm{IU} / \mathrm{kg})$ could induce oocyte maturation and ovulation in all the fish of three groups. Enough volume of good quality ovulated eggs, however, were obtained from fish with oocyte sizes between 700 and $800 \mu \mathrm{m}$.

\section{Relationship between Post-ovulation Time and Fertilization Rate of Eggs in Artificial Insemination}

Ovulation occurred at 42-48 hours after HCG treatment. Changes of fertilization rates with post-ovulation time in artificially inseminated eggs of yellowtail are shown in Fig. 2. The fertilization rates of eggs collected from the eleven fish decreased from $92.5 \%$ ( 0 hour) to $16.7 \%$ (48 hours) with the time proceeded after ovulation. These results suggest that artificial insemination of yellowtail must be carnied out immediately after ovulation in onder to obtain good quality eggs.

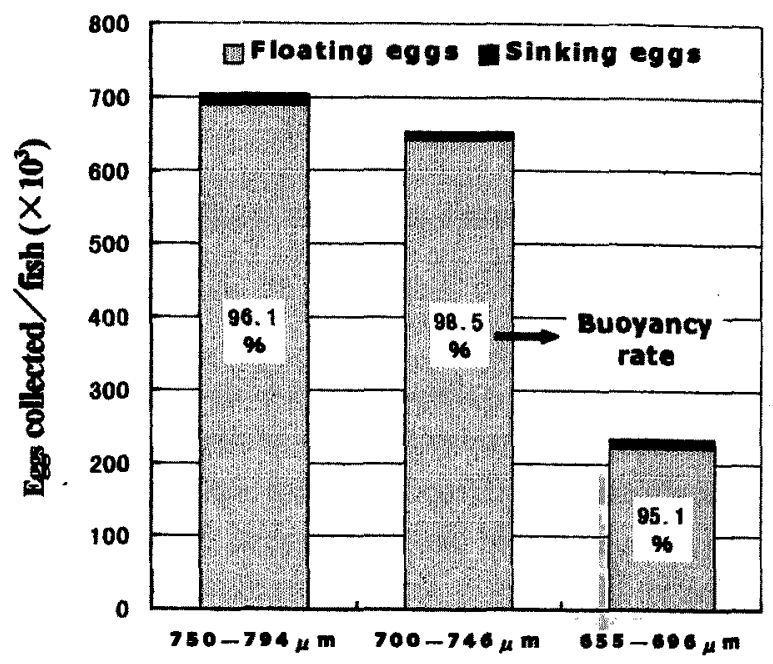

Fig. 1. Eggs collected and egg quality from yellowtail with different oocyte diameter in HCG injection.

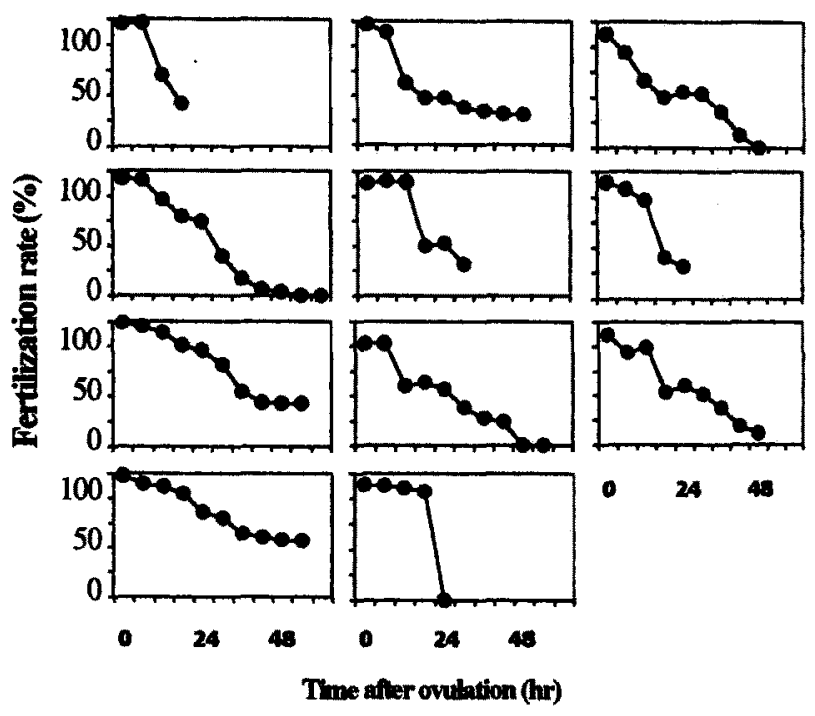

Fig 2 Changes of fertilization rates with post-ovulation time in artificially inserninated yellowtail. Egs of all females were inseminated separately with milt continuously collected from their respective males.

\section{DISCUSSION}

Using our developed methods, enough volume of good quality eggs could be obtained efficiently in yellowtail. In culture practices, the extension of these methods is underway. A stable supply of yellowtail juveniles needed for Japanese mariculture will come to reality in near future. 